\title{
Effect of Environmental Wind on Performance of a 600MW Direct Air-cooled Unit Based on FLUENT
}

\author{
Junfeng $\mathrm{Xu}^{1}$,Taoying $\mathrm{Wang}^{2}$,Minmin $\mathrm{Zhao}^{3,}$ * \\ ${ }^{1}$ SENIOR ENGINEER ,Huadian Electric Power Research Institute, NO. 1 Xiyuan 10 Road, Xihu District, Hangzhou Zhejiang Province, \\ 310030, China \\ ${ }^{2}$ SENIOR ENGINEER, Huadian Electric Power Research Institute, NO. 2 Xiyuan 9 Road, Xihu District, Hangzhou Zhejiang Province, \\ 310030, China \\ ${ }^{3}$ ENGINEER,Huadian Electric Power Research Institute, NO. 2 Xiyuan 9 Road, Xihu District, Hangzhou Zhejiang Province, 310030, \\ China
}

\begin{abstract}
The external flow field of a 600MW air-cooled unit is numerically simulated based on FLUENT. The distribution law of air flow field of air-cooled unit under different wind speed and wind direction conditions is studied. The influence of wind speed and wind direction on the heat transfer performance of aircooled unit is analyzed. Predict the exhaust pressure of direct air-cooled unit under the influence of environmental wind. The results show that in the $+X$ direction environmental wind, the first row of air-cooled unit on the windward side is prone to backflow; in the $+Y$ direction environmental wind, the first row of aircooled unit on the windward side is prone to hot air recirculation. As the wind speed increases, the heat transfer efficiency of the air-cooled unit decreases. The dominant wind direction (WNW) environmental wind has the least impact on the heat transfer efficiency, and the furnace wind ( $+Y$ direction wind) has the greatest influence on the heat transfer efficiency. To improve the heat transfer performance of the air-cooled unit under windy conditions, it is necessary to narrow the range of the negative pressure zone below the air-cooled unit and increase the cooling air flow rate of the air-cooled unit.
\end{abstract}

\section{Introduction}

Under the constraints of water resources, direct air-cooled units have developed rapidly in areas where China is rich in coal and short in water ${ }^{[1]}$. The environmental wind not only reduces the amount of air sucked by the fan, but also increases the temperature of the inhaled air. Some of them also increase the heat transfer resistance of the air-cooled radiator, which seriously affects the heat transfer performance of the air condenser. The influence of the environmental wind is superimposed on unfavorable factors such as high environmental temperature, which can easily cause the unit to run under load and even jump. Therefore, studying the influence of environmental wind, especially strong wind conditions, on the performance of direct air-cooled units is of great significance for improving the safety and economy of its operation.

Domestic and foreign scholars and scientific research institutions have carried out a lot of research work on the influence mechanism and improvement measures of environmental wind on the heat transfer performance of direct air-cooled unit. J.R. Bredell and Meyer et al. ${ }^{[2-3]}$ used FLUENT software to numerically simulate the effect of inlet airflow distortion on the volumetric efficiency of axial fans with different hub ratios. The results show that the fan with a hub ratio of 0.4 has better performance. Increasing the sidewalk at the edge of the air-cooled platform and removing the inlet portion of the edge fan can increase the flow of the peripheral fan and reduce the flow loss of the intake air. Duan Huishen et al ${ }^{[4-5]}$ and Owen et al. ${ }^{[6]}$ studied the formation mechanism of hot air reflow and found through numerical simulation that the higher the wind speed, the more severe the hot air reflow. However, Maulbetsch and DiFilippo ${ }^{[7]}$ found through field tests that at moderate wind speeds $(3 \mathrm{~m} / \mathrm{s}$ to $7 \mathrm{~m} / \mathrm{s})$, hot air reflow was the most serious, and wind inlet air temperature rises most. At higher wind speeds, There is a tendency for the hot air reflow to slow down and slow down. Yang Lijun et al ${ }^{[8-11]}$ studied the layout of a windcooled power station by using numerical simulation method, and the influence of the trapezoidal arrangement on the gas flow and heat transfer characteristics of the aircooled condenser. In the Fluent, the finned tube bundle is simulated with a radiator model, and the influence of the spatial characteristics of the air condenser is considered. Zhou Lanxin et al ${ }^{[12]}$ carried out numerical simulation on the external flow field of air-cooled platform, analyzed the influence of different wind speeds on the heat transfer efficiency of direct air-cooled unit, the causes of air backflow and hot air recirculation on the edge of aircooled platform, and exploring measures to improve heat transfer efficiency of air condensing steam turbines. Zhang Xuelei et al ${ }^{[13]}$ studied the influence of the addition of the raceless vane cascade on the flow field of the air-

*Minmin Zhao: Yasminezhao@163.com 
cooled unit .The heat transfer performance of the aircooled unit is calculated and the structural parameters of the raceless guide vane are optimized. Gu Zhifu et al ${ }^{\text {[14-15] }}$ used wind tunnel simulation experiments to reveal the influence of external wind speed and wind direction on heat transfer efficiency of power plant air cooling system. Research shows that Increasing the height of the aircooled platform and the windshield can effectively reduce the influence of hot air reflow on the air condenser.Gao ${ }^{[16]}$ simplified the air-cooling unit into the flow domain of the cube, and studied the effects of wind speed, wind direction and air-cooled platform height on the heat transfer performance of the air-cooled unit. He et al ${ }^{[17]}$ set up a numerical calculation model for two $600 \mathrm{MW}$ direct air-cooling units, and the study found that the wind speed has a great influence on the performance of the air-cooled condenser. The main reason is that the wind speed causes uneven pressure distribution around the air-cooled platform.

In this paper, a $600 \mathrm{MW}$ direct air-cooled unit is used as the object, and the distribution law of air flow field of air-cooled unit under different wind speed and wind direction conditions is obtained by using FLUENT software. The influence of wind speed and wind direction on the heat transfer performance of air-cooled unit is analyzed. Predict the exhaust pressure of the direct aircooled unit under the influence of environmental wind.

\section{Model and calculation method}

\subsection{Unit overview}

Taking a 600MW direct air-cooled unit and its adjacent cooling tower as an example, the influence of environmental wind to air-cooled unit heat transfer performance is analyzed based on FLUENT software.

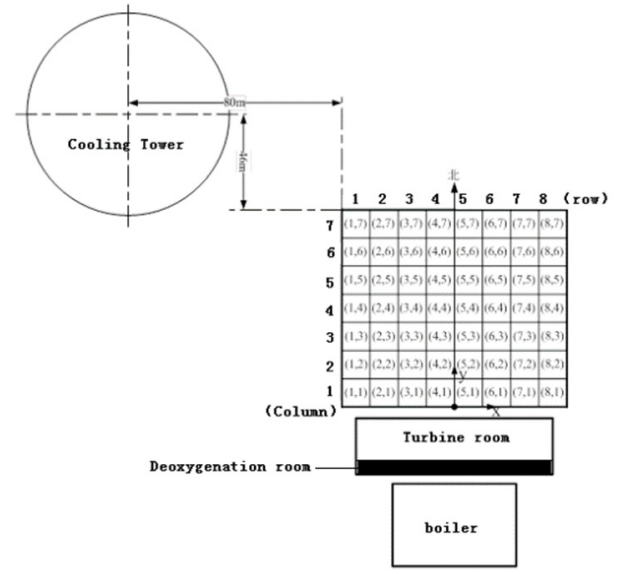

Fig. 2-1. Single unit layout plan

The air condenser is arranged parallel to the column A of the turbine room. Figure 2-1 shows the layout of the single unit boiler room, steam turbine room, oxygen depletion condenser and cooling tower. The length, width and height of the turbine room are $79.2 \mathrm{~m}, 30.6 \mathrm{~m}$ and $38.0 \mathrm{~m}$ respectively; the length, width and height of the deoxygenation room are $79.2 \mathrm{~m}, 10.0 \mathrm{~m}$ and $63.0 \mathrm{~m}$ respectively; the length, width and height of the boiler room are $60.0 \mathrm{~m}, 53 \mathrm{~m}, 93.0 \mathrm{~m}$ respectively. The distance between the turbine room and the air-cooled island (y direction) is $18 \mathrm{~m}$, and the distance between the boiler room and the deoxygenation room is $13 \mathrm{~m}$. The air condensers are arranged in 8 rows and 7 columns, for a total of 56 air cooling units. The air cooling island length (x direction) of a single unit is $91.2 \mathrm{~m}$, and the width (y direction) is $92.4 \mathrm{~m}$. The vertical height of the air-cooled island air-cooled platform is $45 \mathrm{~m}$, the height of the windshield wall is $13 \mathrm{~m}$, and the width of the sidewalk around the air-cooled platform is $1.2 \mathrm{~m}$. For convenience of presentation, each air cooling unit is represented by $\mathrm{U}(\mathrm{i}$, j). Where $i=1,2, \ldots, 8$, represents the number of rows; $j$ $=1,2, \ldots, 7$, represents the number of columns. Natural ventilation cooling tower height is $124 \mathrm{~m}$, air inlet height is $8.3 \mathrm{~m}$, air inlet diameter is $93 \mathrm{~m}$; tower bottom pool diameter is $98.4 \mathrm{~m}$; cooling tower throat height is $93.9 \mathrm{~m}$, throat diameter is $52.4 \mathrm{~m}$; cooling tower outlet diameter is $57 \mathrm{~m}$; packing layer is from ground. $10 \mathrm{~m}$, height is $1 \mathrm{~m}$.

The air-cooled radiator adopts a single-row tube bundle, and the heat exchanger unit is arranged in an isosceles triangle with a top angle of 60 , as shown in Figure 2-2.

\subsection{Simplified models and meshing}

This paper simplifies the heat exchanger unit. The simplified heat exchanger unit model is shown in Figure $2-2$. The rectangular air chamber is used to replace the " $A$ " shaped air chamber. The heat exchanger is located at the top of the rectangular air chamber. The fan is located at the lower part of the rectangular air chamber and sets the heat transfer. The outlet air of the device has the same temperature. This simplification has been proven to be reliable.

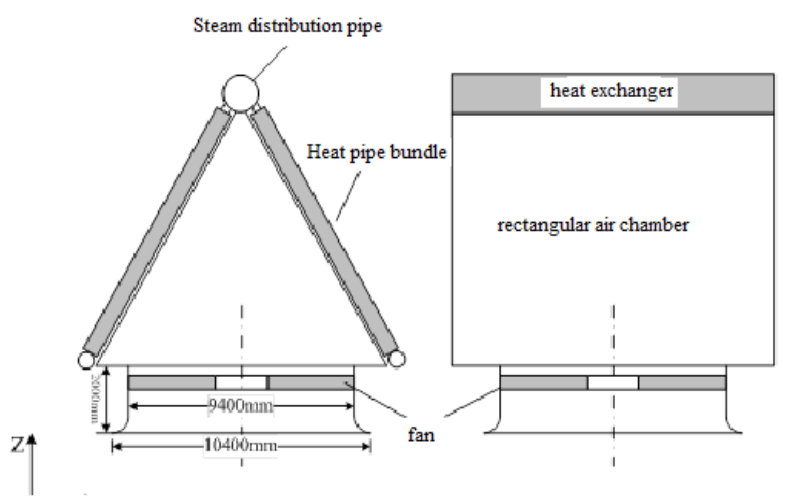

Fig. 2-2. Simplified model of heat exchanger unit

The size of the calculation domain of the air-cooled island numerical analysis model is $\mathrm{X} \times \mathrm{Y} \times \mathrm{Z}=600 \mathrm{~m} \times$ $600 \mathrm{~m} \times 300 \mathrm{~m}$. Meshing with Gambit software. A structured grid partitioning model is used and local encrypt certain key areas. The heat exchanger unit is divided by a combination of a structured grid and an unstructured grid. In the $+X$ direction $3 \mathrm{~m} / \mathrm{s}$ wind speed, the model with the number of grids of 1.16 million, 1.59 
million, 1.76 million was calculated and compared. When the number of grids is 1.59 million and 1.76 million, the relative error of the total heat transfer of the air-cooled unit is $0.67 \%$, and the relative error of the average air flow of the heat exchanger unit is $0.85 \%$, both less than $1 \%$. Therefore, a model with a grid number of 1.59 million is selected for calculation. The grid drawn is shown in Figure 2-3.

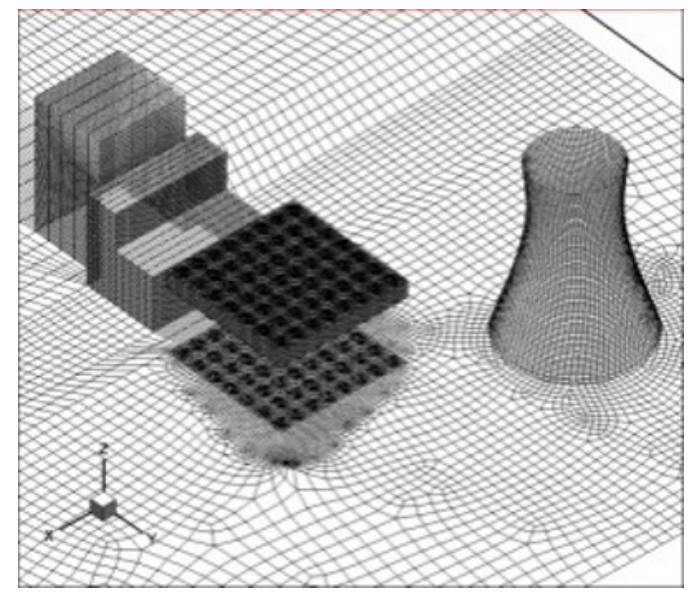

Fig. 2-3. Meshing

\subsection{Numerical calculation method}

\subsubsection{Turbulence model and buoyancy model}

The standard $k-\varepsilon$ model is used to solve the external air flow field of the air-cooled unit. The standard $k-\varepsilon$ model is currently the simplest and complete turbulence model, which is widely used in the simulation of industrial flow fields and heat exchange. The main governing equations used in numerical simulation are continuity equation, constitutive equation, $\mathrm{N}-\mathrm{S}$ equation, turbulent flow energy equation, and diffusivity equation:

continuity equation:

$$
\frac{\partial \rho}{\partial t}+\nabla \cdot(\rho \vec{v})=0
$$

constitutive equation:

$$
\tau_{i j}=2 \mu \varepsilon_{i j}-\frac{2}{3} \mu \nabla \cdot \vec{v} I_{i j}
$$

N-S equation:

$$
\rho \frac{d u_{i}}{d t}=\rho f_{i}-\frac{\partial p}{\partial x_{i}}+\mu \frac{\partial^{2} u_{i}}{\partial x_{j} \partial x_{j}}
$$

turbulent flow energy equation:

$$
\bar{u}_{j} \frac{\partial k}{\partial x_{j}}=C_{k} \frac{\partial}{\partial x_{j}}\left(\frac{k^{2}}{\varepsilon} \frac{\partial k}{\partial x_{j}}\right)-\overline{u_{i}^{\prime} u_{j}^{\prime}} \frac{\partial \overline{u_{i}}}{\partial x_{j}}+v \frac{\partial^{2} k}{\partial x_{j} \partial x_{j}}-\varepsilon
$$

diffusivity equation:

$$
\bar{u}_{j} \frac{\partial \varepsilon}{\partial x_{j}}=\frac{\partial}{\partial x_{j}}\left[C_{\varepsilon} \frac{k^{2}}{\varepsilon} \frac{\partial \varepsilon}{\partial x_{j}}+v \frac{\partial \varepsilon}{\partial x_{j}}\right]+C_{\varepsilon 1} \frac{\varepsilon}{k}\left(-\overline{u_{i}^{\prime} u_{j}^{\prime}}\right) \frac{\partial \bar{u}_{i}}{\partial x_{j}}-C_{\varepsilon 2} \frac{\varepsilon^{2}}{k}
$$

Where: $\rho$ means fluid density $\mathrm{kg} / \mathrm{m}^{3} ; \vec{v}$ means velocity vector; $\tau_{i j}$ means stress tensor; $\varepsilon_{i j}$ means strain rate tensor; $p$ means pressure, $\mathrm{Pa} ; \mu$ means hydrodynamic viscosity coefficient; $u$ means speed, $i$, $j=1,2,3 ; u^{\prime} 、 \bar{u}$ means instantaneous speed and time average speed respectively. $\mathrm{C}_{\mu}=0.09 、 C_{k}=0.225$ 、 $C_{\varepsilon}=0.13 、 C_{\varepsilon 1}=1.45 、 C_{\varepsilon 2}=1.92$ 。

The buoyancy term needs to be opened in consideration of the natural ventilation effect when air flows through the air-cooled unit and the cooling tower. For incompressible fluids, the buoyancy generated by the difference in air density is generally calculated according to the Boussinesq model in order to facilitate computational convergence. The Boussinesq model assumes that the fluid density is constant, but only changes the volumetric force of the momentum equation along the direction of gravity, ie:

$$
F_{z}=\left(\rho-\rho_{\mathrm{a}}\right) g \approx \rho_{\mathrm{a}} \beta_{\mathrm{T}}\left(T-T_{\mathrm{a}}\right) g
$$

Where, $\rho_{\mathrm{a}}$ means air density, this paper takes $1.054 \mathrm{~kg} / \mathrm{m}^{3}$; Ta means air operating temperature, taken $287.15{ }^{\circ} \mathrm{C} ; \quad \beta_{\mathrm{T}}$ means the coefficient of thermal expansion of air, taken $0.0033 ; g$ means gravity acceleration, this paper takes $-9.81 \mathrm{~m} / \mathrm{s}^{2},-Z$ direction;

\subsubsection{Boundary conditions}

(1) Domain boundary conditions

Table 2-1 Boundary condition settings for the domain

\begin{tabular}{|c|c|c|c|c|}
\hline $\begin{array}{c}\text { Bound } \\
\text { ary }\end{array}$ & $\begin{array}{c}\text { No } \\
\text { wind }\end{array}$ & $+\mathbf{X}$ & $+\mathbf{Y}$ & $\mathbf{W N W}$ \\
\hline ABCD & $\begin{array}{c}\text { pressure } \\
\text {-inlet }\end{array}$ & symmetry & $\begin{array}{c}\text { velocity- } \\
\text { inlet }\end{array}$ & outflow \\
\hline BEFC & $\begin{array}{c}\text { pressure } \\
\text {-inlet }\end{array}$ & outflow & symmetry & outflow \\
\hline EFGH & $\begin{array}{c}\text { pressure } \\
\text {-inlet }\end{array}$ & symmetry & outflow & $\begin{array}{c}\text { velocity- } \\
\text { inlet }\end{array}$ \\
\hline ADGH & $\begin{array}{c}\text { pressure } \\
\text {-inlet }\end{array}$ & $\begin{array}{c}\text { velocity- } \\
\text { inlet }\end{array}$ & symmetry & $\begin{array}{c}\text { velocity- } \\
\text { inlet }\end{array}$ \\
\hline ABEH & wall & wall & wall & wall \\
\hline CDGF & $\begin{array}{c}\text { pressure } \\
\text {-outlet }\end{array}$ & symmetry & symmetry & symmetry \\
\hline
\end{tabular}

The boundary conditions of the domain are set as shown in Figure 2-4 and Table 2-1. 


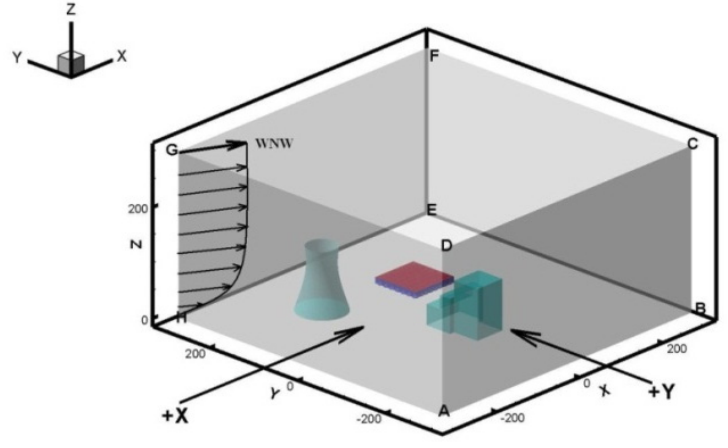

Fig. 2-4. Computational domain and wind direction

In an atmosphere a few meters above the ground, the relationship between mean wind speed and altitude is described by the atmospheric boundary layer function, Deacon's power law:

$$
v_{i}=v_{0}\left(\frac{z_{i}}{z_{0}}\right)^{b}
$$

Where: $z_{0}$ is the installation height when measuring the wind speed with an anemometer, generally $10 \mathrm{~m} ; v_{0}$ is the average wind speed at $z_{0}, \mathrm{~m} / \mathrm{s} ; \mathrm{z}_{\mathrm{i}}$ is any height, $\mathrm{m} ; v_{i}$ is the average wind speed at $z_{i}, \mathrm{~m} / \mathrm{s} ; b$ is the ground roughness coefficient, according to VGB-131Me, $b$ is 0.2 .

UDF is used to program the above formula as a boundary condition for environmental wind initialization.

(2) Air-cooled radiator

Air-cooled radiator uses porous media boundary conditions. In order to simulate the flow resistance of air in the heat exchanger unit, it is necessary to add a corresponding momentum source term in the momentum equation. The momentum source term of the porous medium consists of two parts: the viscous loss term and the inertia loss term, as shown in equation (2-8):

$$
S_{i}=-\frac{\Delta p}{l}=-\left(\frac{\mu}{\alpha_{i}} u_{i}+C_{i} \frac{1}{2} \rho_{\mathrm{a}}|\boldsymbol{u}| u_{i}\right)
$$

Where: $C_{i}, 1 / \alpha_{i}$ are the inertial drag coefficient and viscous drag coefficient in the $i$ direction; $\mu$ is the dynamic viscosity coefficient, $\mathrm{Pa} \cdot \mathrm{s} ; \boldsymbol{u}$ is the velocity vector; $\rho_{a}$ is the air density, $\mathrm{kg} / \mathrm{m}^{3} ; u_{i}$ is the speed in the $i$ direction, $\mathrm{m} / \mathrm{s} ; \Delta p$ is the radiator pressure drop, $\mathrm{Pa} ; l$ is the thickness of the radiator, $m$.

(3) Fan

The axial flow fan of each heat exchanger unit is simulated by the Fan model in Fluent. According to the fan characteristic curve, the relationship between the static pressure $p_{\mathrm{fs}}$ of the fan and the average wind speed $v_{\mathrm{f}}$ is:

$$
p_{\mathrm{fs}}=-1.77 v_{\mathrm{f}}^{2}+2.92 v_{\mathrm{f}}+116.14
$$

(4) Cooling tower

To study the influence of the cooling tower on the external air flow field of the direct air-cooled unit under strong wind conditions, only the flow and heat transfer process of the single phase fluid (air) in the cooling tower need to be considered. The packing layer in the cooling tower is set according to the boundary conditions of the porous medium. An energy source term is added to the boundary conditions of the porous layer of the filler layer to simulate the heat exchange between the air and the cooling water. Under the design conditions, the heat absorption of the cooling air is about $131.1 \mathrm{MW}$.

(5) Other

The boiler room and the turbine room are all set as solid boundaries, and the boiler room is set as a wall with heat source to better study the furnace later wind $(+Y$ direction). The heat dissipation per unit area of the boiler is calculated to be $463.9 \mathrm{~W}$.

\section{Calculation results and analysis}

\subsection{Calculation conditions}

Based on the SIMPLE algorithm, the standard $k-\varepsilon$ turbulence model was used to simulate the air-cooled units under windless conditions, $+\mathrm{X}$ direction (west wind), $+\mathrm{Y}$ direction (south wind), WNW direction (dominant wind direction). The environmental temperature is $14^{\circ} \mathrm{C}$, the atmospheric pressure is $86.9 \mathrm{kPa}$, the exhaust steam pressure is $12 \mathrm{kPa}$, the exhaust steam pressure loss is 1.6 $\mathrm{kPa}$, and the saturation temperature corresponding to the air condenser pressure is $46.6^{\circ} \mathrm{C}$.

\subsection{Heat exchange capacity and heat transfer efficiency}

The heat exchange amount $Q_{\text {acc }}$ of the air condenser is:

$$
Q_{\mathrm{acc}}=\sum_{i=1}^{8} \sum_{j=1}^{7} Q_{a, i j}=\sum_{i=1}^{8} \sum_{j=1}^{7} \mathrm{G}_{\mathrm{a}, i j} c_{\mathrm{pa}}\left(t_{a 2, i j}-t_{a 1, i j}\right)
$$

Where: $i, j$ are the rows and columns of the air cooling unit; $G_{a, i j}$ is cooling air flow rate of heat exchanger unit $\mathrm{U}(\mathrm{i}, \mathrm{j}), \mathrm{kg} / \mathrm{s} ; C_{\mathrm{pa}}$ is constant pressure of air; $t_{a 2}, i j$ is the average air temperature of the heat exchanger unit $U(i, j)$, this paper taken $318.5 \mathrm{~K} ; t_{a 1, i j}$ : is heat exchanger unit $U(i$, j) inlet air average temperature, $\mathrm{K}$;

Based on the heat exchange capacity of the air-cooled unit under windless conditions, the heat transfer efficiency of the air-cooled unit under strong wind conditions is defined as:

$$
\eta_{\mathrm{h}}=\frac{Q_{\mathrm{acc}}^{\text {windy }}}{Q_{\mathrm{acc}}^{\text {windless }}}
$$

\subsection{Heat transfer performance of air-cooled unit under no wind conditions}

The temperature field, pressure field and streamline diagram of the $j=4$ plane under windless conditions are shown in Figure 3-1. 

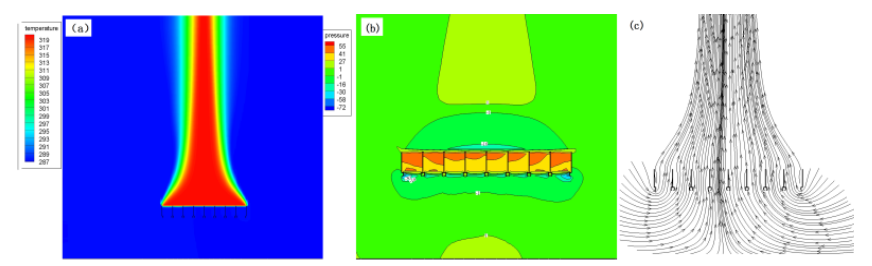

Fig.3-1. $\mathrm{j}=4$ plane flow field characteristics (a) temperature field (b) pressure field (c) ctreamline diagram

The temperature field, pressure field and streamline diagram of the $i=5$ plane under windless conditions are shown in Figure 3-2.
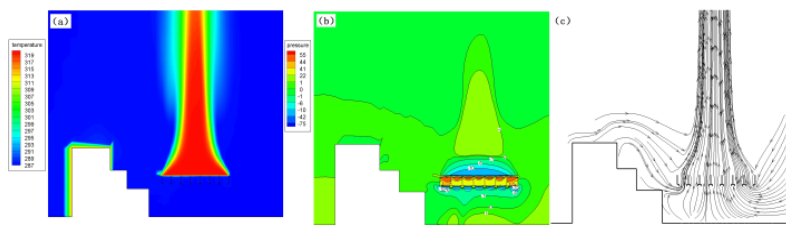

Fig.3-2. i=4 plane flow field characteristics (a) temperature field (b) pressure field (c) streamline diagram

Figure 3-3 shows the cooling air flow, inlet average temperature and heat exchange capacity of each heat exchanger unit under windless conditions.

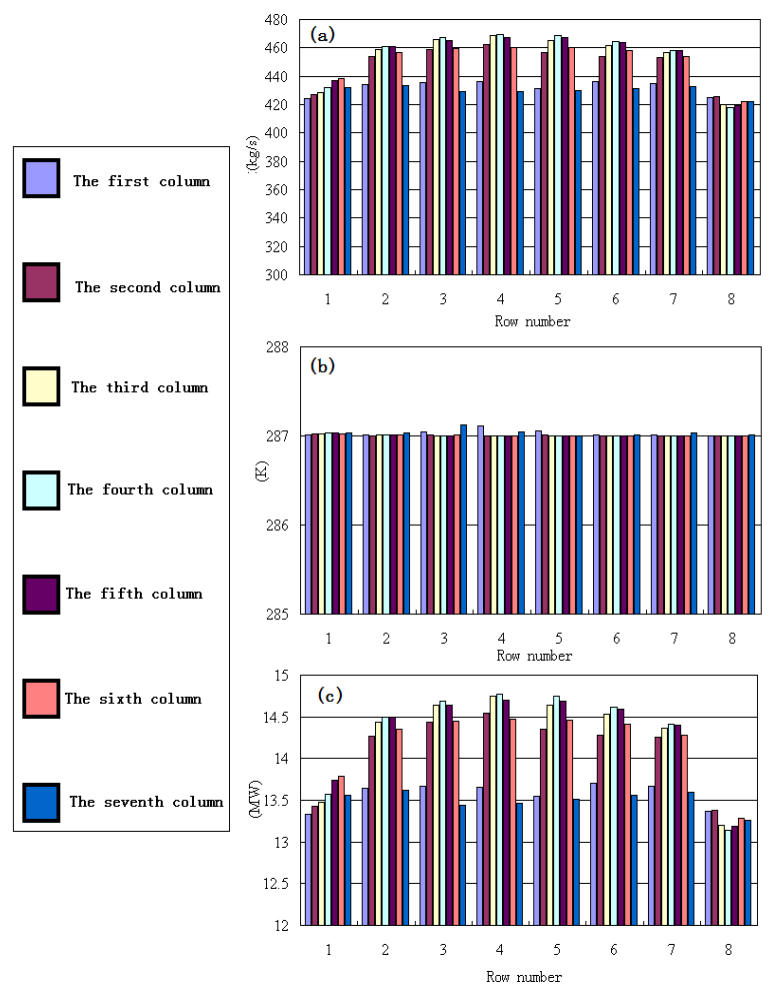

Fig.3-3. Heat transfer performance of heat exchanger unit under windless conditions (a) mass flow rate (b) average inlet temperature (c) heat exchange capacity

It can be seen from Fig. 3-3 that the air mass flow rate of the edge heat exchanger unit is lower than that of the internal heat exchanger unit under windless conditions. The main reason is that a negative pressure zone is formed near the air inlet of the edge heat exchanger unit, which affects the performance of the fan. For example, the pressure extreme value of the negative pressure zone below the fan of the $j=4$ plane is $-72 \mathrm{~Pa}$, and the pressure extreme value of the negative pressure zone below the fan of the plane $i=5$ is $-75 \mathrm{~Pa}$. Under the windless condition, the average inlet temperature of each heat exchanger unit is basically equal, which is equal to $287 \mathrm{~K}$, which means that there will be no hot air recirculation or backflow in each heat exchanger unit under windless conditions, which can be verified from the streamline diagram. The streamline diagram also shows that the air flow of each heat exchanger unit exhibits better symmetry under windless conditions.

It can be seen from Fig. 3-3(c) that the air mass flow rate of the edge heat exchanger unit is lower than that of the internal heat exchanger unit. The calculation results show that the total heat exchange capacity of the aircooled unit under the windless condition is $786 \mathrm{MW}$.

\subsection{External flow field characteristics of air- cooled unit under $+X$ direction environmental wind conditions}

The temperature field, pressure field and streamline diagram of $j=4$ plane in $+X$ direction are shown in Figure 3-4, Figure 3-5, Figure 3-6, respectively.

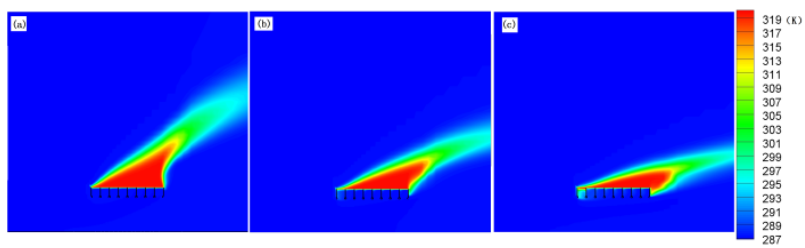

Fig.3-4. Temperature field distribution in $+\mathrm{X}$ direction environmental wind (a) $3 \mathrm{~m} / \mathrm{s}$ (b ) $6 \mathrm{~m} / \mathrm{s}$ (c) $9 \mathrm{~m} / \mathrm{s}$

As can be seen from Figure 3-4, because of the influence of environmental wind, the temperature contour map is inclined, and the higher the wind speed, the larger the tilt angle. It can also be seen from Figure 3-4 that the first row of heat exchanger units on the windward side is greatly affected by the environmental wind. As the wind speed increases, the temperature of the air in the first row of heat exchanger units increases significantly. When the wind speed reaches $9 \mathrm{~m} / \mathrm{s}$, even the phenomenon of "backflow" occurs.

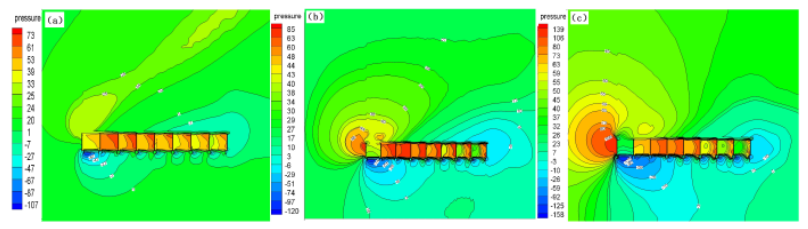

Fig.3-5. Pressure field distribution in $+X$ direction environmental wind (a) $3 \mathrm{~m} / \mathrm{s}$ (b) $6 \mathrm{~m} / \mathrm{s}$ (c) $9 \mathrm{~m} / \mathrm{s}$

It can be seen from Figure 3-5 that under environmental wind conditions, there is a certain negative pressure zone at the inlet of each fan, and the first row of fan on the windward side is most affected. The higher the environmental wind speed, the larger the range of negative pressure zones formed under the fan, and the lower the 
static pressure value in the inlet area of the fan, the greater the impact on the performance of the fan. For example, when the wind speed is $3 \mathrm{~m} / \mathrm{s}$, the minimum static pressure at the inlet area of the fan is $-107 \mathrm{~Pa}$; when the wind speed is $6 \mathrm{~m} / \mathrm{s}$, the minimum static pressure at the inlet area of the fan is $-120 \mathrm{~Pa}$; when the wind speed is $9 \mathrm{~m} / \mathrm{s}$, the minimum static pressure at the inlet area of the fan is $158 \mathrm{~Pa}$, which is also the cause of the "backflow" phenomenon.

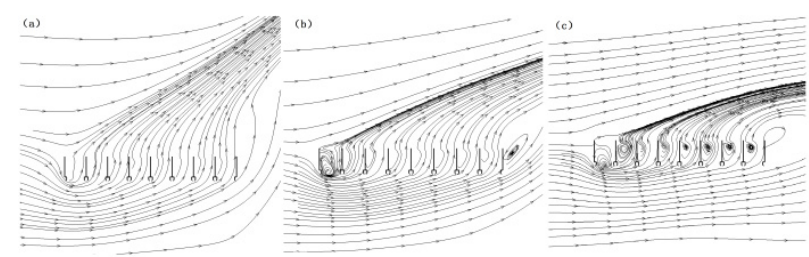

Fig.3-6. Streamline diagram in $+X$ direction environmental wind (a) $3 \mathrm{~m} / \mathrm{s}$ (b) $6 \mathrm{~m} / \mathrm{s}$ (c) $9 \mathrm{~m} / \mathrm{s}$

As can be seen from Fig. 3-6, when the wind speed is small, the range of the eddy current zone in each heat exchanger unit is small. When the wind speed is $9 \mathrm{~m} / \mathrm{s}$, there is a vortex zone in almost every heat exchanger unit.

\subsection{External flow field characteristics of air- cooled unit under $+Y$ direction environmental wind conditions}

The temperature field, pressure field and streamline diagram in the $+Y$ direction are shown in Figure 3-7, Figure 3-8, Figure 3-9, respectively.

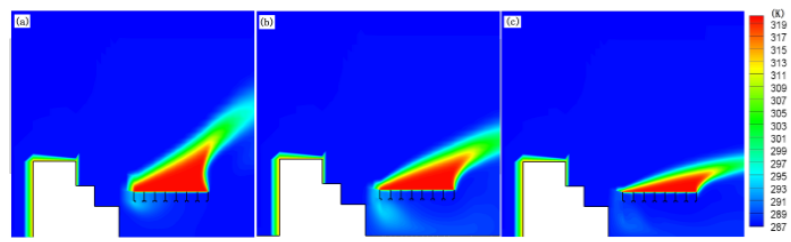

Fig.3-7. Temperature field distribution in $+\mathrm{Y}$ direction environmental wind (a) $3 \mathrm{~m} / \mathrm{s}$ (b) $6 \mathrm{~m} / \mathrm{s}$ (c) $9 \mathrm{~m} / \mathrm{s}$

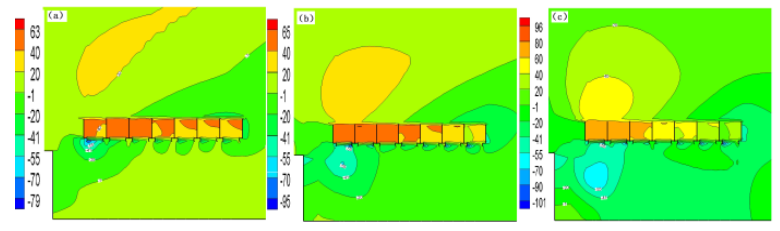

Fig.3-8. Pressure field distribution in $+Y$ direction environmental wind (a) $3 \mathrm{~m} / \mathrm{s}$ (b) $6 \mathrm{~m} / \mathrm{s}$ (c) $9 \mathrm{~m} / \mathrm{s}$

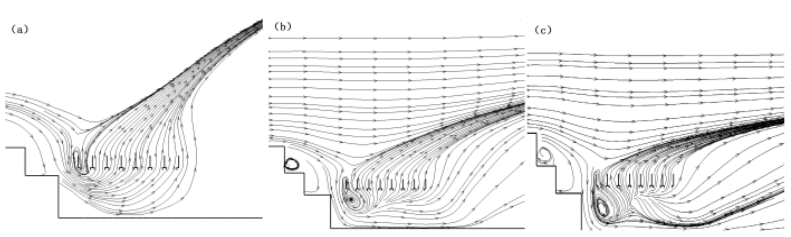

Fig.3-9. Streamline diagram in $+Y$ direction environmental wind (a) $3 \mathrm{~m} / \mathrm{s}(\mathrm{b}) 6 \mathrm{~m} / \mathrm{s}$ (c) $9 \mathrm{~m} / \mathrm{s}$
It can be seen from Fig. 3-7, Fig. 3-8, Fig. 3-9 that in $+\mathrm{Y}$ direction environmental wind, hot air recirculation occurs in the heat exchanger unit in the first row on the windward side, resulting in the air temperature rises in the first row of the heat exchanger unit on the windward side.. The higher the environmental wind speed, the larger the range of the vortex zone below the heat exchanger unit and the more severe the hot air reflow.

Due to the blockage of the boiler and the steam turbine, in the $+Y$ direction ,the static pressure near the suction port of the fifth row fan is higher than that of the $+X$ direction, but the range of the negative pressure region is greatly increased. In the $+Y$ direction environmental wind, a vortex zone is formed below the air intake of the fan, and the range of the vortex zone also increases as the wind speed increases.

It also be seen from Fig. 3-7 that the air temperature in the first column of the heat exchanger unit on the windward side is the highest when the wind speed is $3 \mathrm{~m} / \mathrm{s}$. As the wind speed increases, the range of the vortex zone below the heat exchanger unit expands and the center of the vortex zone moves downwards, so that the reflow hot air and the cold air are more fully exchanged, and the air temperature sucked by the heat exchanger unit is lowered.

\subsection{External flow field characteristics of air- cooled unit under WNW direction environmental wind conditions}

The temperature field, pressure field and streamline diagram of $j=4$ plane in $\mathrm{WNW}$ direction are shown in Figure 3-10, Figure 3-11, Figure 3-12, respectively.
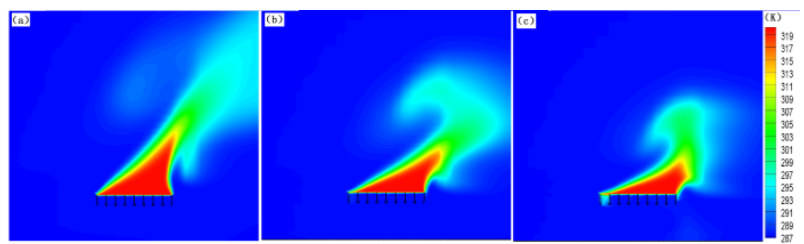

Fig.3-10. Temperature field distribution in WNW direction environmental wind (a) $3 \mathrm{~m} / \mathrm{s}$ (b) $6 \mathrm{~m} / \mathrm{s}$ (c) $9 \mathrm{~m} / \mathrm{s}$

It can be seen from Fig. 3-10 that under the influence of the environmental wind in the WNW direction, the temperature contour map is inclined, and the higher the wind speed, the larger the tilt angle. The first row of heat exchanger units on the windward side is greatly affected by the environmental wind. As the wind speed increases, the temperature of the air in the first row of heat exchanger units increases significantly. This shows that under the influence of the environmental wind in the WNW direction, the first row of heat exchanger units has a phenomenon of backflow, and the phenomenon of backflow becomes more serious with the increase of wind speed.
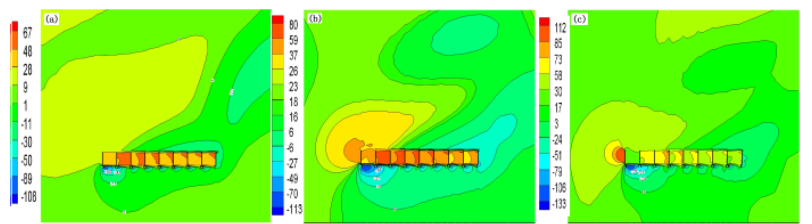
Fig.3-11. Pressure field distribution in WNW direction environmental wind (a) $3 \mathrm{~m} / \mathrm{s}$ (b) $6 \mathrm{~m} / \mathrm{s}$ (c) $9 \mathrm{~m} / \mathrm{s}$

It can be seen from Fig. 3-11 that under the wind conditions of $\mathrm{WNW}$ direction, there is a certain negative pressure zone at the inlet of each fan, and the first row of fan on the windward side is most affected. As the wind speed increases, the larger the range of negative pressure zones formed under the fan, the lower the static pressure extreme value in the inlet area of the fan, and the greater the impact on the performance of the fan. For example, when the wind speed is $3 \mathrm{~m} / \mathrm{s}$, the static pressure extreme value of the negative pressure zone of the fan at the inlet area is $-108 \mathrm{~Pa}$; when the wind speed is $6 \mathrm{~m} / \mathrm{s}$, the static pressure extreme value of the negative pressure zone of the fan at the inlet area is $-113 \mathrm{~Pa}$; the wind speed is $9 \mathrm{~m} / \mathrm{s}$. the static pressure extreme value of the negative pressure zone of the fan a the inlet area is $-133 \mathrm{~Pa}$, which is also the main reason for the decrease of the performance of the fan and the decrease of the cooling air flow of the heat exchanger unit.

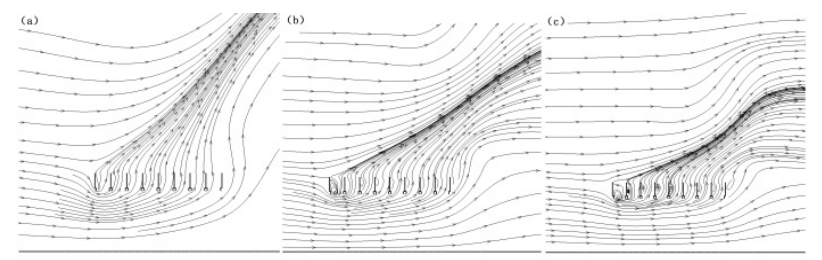

Fig.3-12.Streamline diagram in WNW direction environmental wind (a) $3 \mathrm{~m} / \mathrm{s}$ (b) $6 \mathrm{~m} / \mathrm{s}$ (c) $9 \mathrm{~m} / \mathrm{s}$

It can be seen from Fig. 3-12 that when the wind speed is $3 \mathrm{~m} / \mathrm{s}$, there is almost no eddy current zone in each heat exchanger unit; when the wind speed is $6 \mathrm{~m} / \mathrm{s}$, there is a large eddy current zone at the inlet of the first row on the windward side; When the wind speed is $9 \mathrm{~m} / \mathrm{s}$, there are obvious eddy current zones in the first to fifth rows of heat exchanger units.

\subsection{Heat exchange capacity and heat transfer efficiency}

In the $+\mathrm{X},+\mathrm{Y}$, and $\mathrm{WNW}$ direction environmental winds, the heat transfer efficiency of the air-cooled unit is shown in Figure 3-13.

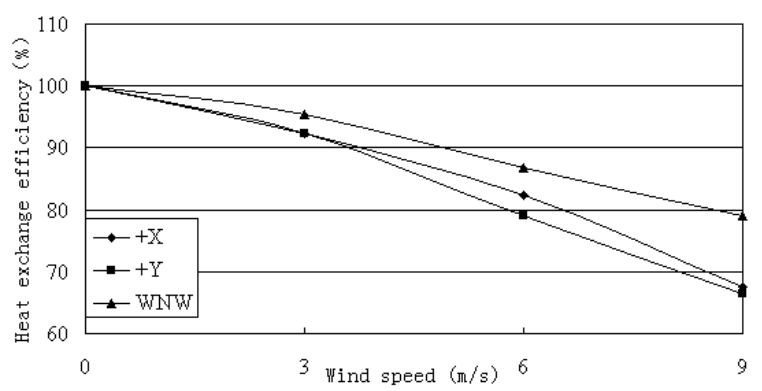

Fig.3-13. Heat transfer efficiency of a air-cooled unit at different wind speeds

It can be seen from Fig. 3-13 that as the wind speed increases, the heat transfer efficiency of the air-cooled unit decreases. At the same wind speed, the dominant wind direction (WNW) has the least influence on the air-cooled unit, and its heat exchange efficiency is the highest; the furnace later wind ( $+Y$ direction environmental wind) has the greatest influence on the air-cooled unit, and the least heat exchange efficient.

According to the distribution law of air flow field obtained by numerical simulation results, there are two main factors affecting the heat transfer efficiency of direct air-cooled unit: (1) hot air reflow or backflow will cause the temperature of the fan to rise, thus reducing the heat exchange efficiency of the air-cooled unit; (2) the presence of the negative pressure zone near the suction port of the fan will result in a decrease in the performance of the fan, and the flow of cooling air flowing through the heat exchanger unit is reduced, thereby reducing the heat exchange capacity of the air-cooled unit. Figure 3-14 shows the relationship between the heat transfer and the wind speed of the air-cooled unit in different wind direction. The dotted line in the figure indicates that when there is no hot air return or backflow (the average inlet temperature of each heat exchanger unit is $287 \mathrm{~K}$ ), the heat exchange capacity of air-cooled unit.
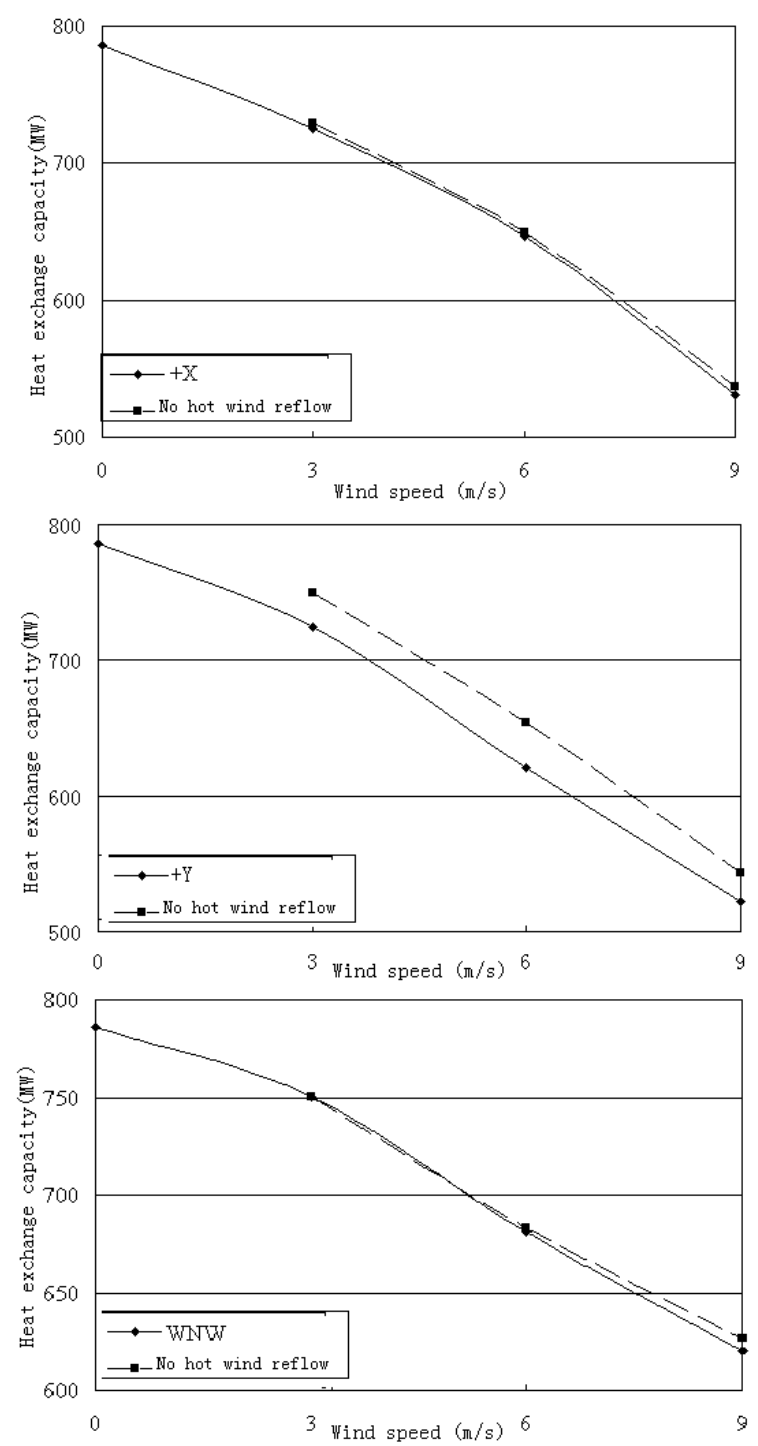
Fig.3-14. Heat exchange capacity of the air-cooled unit at different wind speeds (a) $+\mathrm{X}$ direction (b) $+\mathrm{Y}$ direction (c) WNW direction

In order to obtain the dominant factors of affecting the heat transfer performance of the air-cooled unit in different wind directions, this paper calculates the weight of the two factors. The weight of the influence of the negative pressure zone on the heat transfer performance of the air-cooled unit is defined as:

$$
X_{\text {Fan }}=\frac{Q_{\text {acc }}^{\text {windless }}-Q_{\mathrm{acc}}^{287}}{Q_{\mathrm{acc}}^{\text {windless }}-Q_{\mathrm{acc}}^{\text {windy }}}
$$

The weight of the effect of hot air recirculation on the heat transfer performance of the air-cooled unit is defined as:

$$
X_{\mathrm{HR}}=1-X_{\mathrm{Fan}}
$$

In the formula, $Q_{\text {acc }}^{\text {windless }} 、 Q_{\text {acc }}^{\text {windy }}$ means heat exchange capacity of the air-cooled unit under windless and windy conditions; $Q_{\text {acc }}^{287}$ means the heat exchange capacity of the air-cooled unit without hot air return or backflow in windy conditions;

Table 3-1 gives the weights of the influence of the negative pressure zone and hot air return on the heat transfer performance of the air-cooled unit. It can be seen from Table 3-1 that the hot air return in the $+Y$ direction has a larger weight, and the hot air return in the $+X$ direction has a smaller weight. Under various working conditions, the dominant factor affecting the heat transfer performance of the air-cooled unit is the reduction of the cooling air volume of the heat exchanger unit caused by the presence of the negative pressure zone. Therefore, in order to improve the heat transfer performance of the aircooled unit under strong wind conditions, it is necessary to narrow the range of the negative pressure zone below the heat exchanger unit and increase the cooling air flow rate of the heat exchange unit.

Table 3-1 Weights affecting the heat transfer performance of air-cooled unit

\begin{tabular}{|c|c|c|c|}
\hline \multicolumn{2}{|c|}{$\begin{array}{c}\text { Wind direction } / \\
\text { wind speed }\end{array}$} & $\begin{array}{c}\text { Negative pressure } \\
\text { zone weight }\end{array}$ & $\begin{array}{c}\text { hot air return } \\
\text { weight }\end{array}$ \\
\hline \multirow{3}{*}{$+\mathrm{X}$} & $3 \mathrm{~m} / \mathrm{s}$ & $93.3 \%$ & $6.7 \%$ \\
\cline { 2 - 4 } & $6 \mathrm{~m} / \mathrm{s}$ & $98.0 \%$ & $2.0 \%$ \\
\cline { 2 - 4 } & $9 \mathrm{~m} / \mathrm{s}$ & $97.6 \%$ & $2.4 \%$ \\
\hline \multirow{3}{*}{$+\mathrm{Y}$} & $3 \mathrm{~m} / \mathrm{s}$ & $59.1 \%$ & $40.9 \%$ \\
\cline { 2 - 4 } & $6 \mathrm{~m} / \mathrm{s}$ & $79.7 \%$ & $20.3 \%$ \\
\cline { 2 - 4 } & $9 \mathrm{~m} / \mathrm{s}$ & $91.7 \%$ & $8.3 \%$ \\
\hline \multirow{3}{*}{$\mathrm{WNW}$} & $3 \mathrm{~m} / \mathrm{s}$ & $98.5 \%$ & $1.5 \%$ \\
\cline { 2 - 4 } & $6 \mathrm{~m} / \mathrm{s}$ & $98.2 \%$ & $1.8 \%$ \\
\cline { 2 - 4 } & $9 \mathrm{~m} / \mathrm{s}$ & $96.6 \%$ & $3.4 \%$ \\
\hline
\end{tabular}

\section{Prediction of exhaust pressure of direct air-cooled unit under the influence of environmental wind}

For a specific air-cooled unit, the air temperature will deviate from the design value in actual operation, and the wind direction and wind speed will also change, resulting in changes in the inlet air temperature and air volume of the heat exchanger unit, so that the exhaust steam pressure deviates from the design value. Therefore, the calculation method of exhaust pressure under the influence of environmental wind is the key to the calculation of the performance of air-cooled unit.

\subsection{Problems in the calculation of the performance of the direct air-cooled unit}

When the exhaust pressure of the direct air-cooled unit is traditionally calculated, the air-cooled island is calculated as a whole from the macroscopic view. It is considered that the air volume and steam volume of the heat exchanger units are equal, ignoring the difference in heat exchange area, air volume, and steam amount of each heat exchanger unit, and the calculation results are inevitably biased.

When there is an environmental wind, hot air reflow, backflow, etc. may occur, so that the inlet air temperature of the heat exchanger unit changes, no longer equal to the environmental temperature, and the inlet air temperatures of the heat exchanger units are also different from each other. The occurrence of hot air reflow and backflow will also cause the air flow and physical properties of the air heat exchanger to be different from each other. Based on the numerical simulation results of each heat exchanger unit, the calculation scale of the unit's exhaust steam pressure is refined from the air-cooled unit to the heat exchanger unit, and the calculation model of the exhaust pressure of the direct air-cooled unit under the influence of environmental wind is established.

\subsection{Simplified calculation of heat transfer coefficient of each heat exchanger unit}

The calculation method of heat transfer coefficient of heat exchanger unit is given in ${ }^{[18]}$. In the case that the heat exchanger unit has a certain windward area, the magnitude of the oncoming wind speed depends on the mass flow of air in the heat exchanger unit, namely:

$$
\frac{K_{\mathrm{ij}, \mathrm{od}}}{K_{\mathrm{ij}}}=\left[\frac{\left(v_{\mathrm{NF}, \mathrm{ij}}\right)_{\mathrm{od}}}{v_{\mathrm{NF}, \mathrm{ij}}}\right]^{0.6}=\left[\frac{\left(G_{\mathrm{a}, \mathrm{ij}}\right)_{\mathrm{od}}}{G_{\mathrm{a}, \mathrm{ij}}}\right]^{0.6}
$$

Where, $G_{a, i j}$ means the air mass flow rate of the heat exchanger unit $\mathrm{U}(\mathrm{i}, \mathrm{j})(\mathrm{kg} / \mathrm{s}) ; K_{i j}$ means heat transfer coefficient of the heat exchanger unit $\mathrm{U}(\mathrm{i}, \mathrm{j})\left(\mathrm{W} /\left(\mathrm{m}^{2} \cdot \circ\right.\right.$ C)).

Thus, according to the air mass flow rate of each heat exchanger unit obtained by numerical simulation, the heat transfer coefficient under variable operating conditions can be calculated from the equation (4-1).

4.3 Calculation of exhaust pressure of direct aircooled unit under the influence of environmental wind 


\subsubsection{Calculation of saturation temperature in heat exchanger unit}

According to the $\varepsilon$-NTU method, the saturation temperature in the heat exchanger unit $U(i, j)$ can be calculated as follows:

$$
\begin{gathered}
t_{\mathrm{n}, \mathrm{ij}}=\frac{Q_{\mathrm{n}, \mathrm{ij}}}{G_{\mathrm{a}, \mathrm{ij}} c_{\mathrm{pa}}} \times \frac{1}{1-e^{-N T U_{\mathrm{ij}}}}+t_{\mathrm{a} 1, \mathrm{ij}} \\
N T U_{\mathrm{ij}}=\frac{K_{\mathrm{ijj}} S_{\mathrm{ijj}}}{G_{\mathrm{a}, \mathrm{ij}} c_{\mathrm{pa}}}
\end{gathered}
$$

Where the lower corner $i j$ represents the parameters of the heat exchanger unit $\mathrm{U}(\mathrm{i}, \mathrm{j}) ; t_{\mathrm{a} 1, \mathrm{j} j}$ means the average temperature of the air at the outlet of the heat exchanger unit $\mathrm{U}(\mathrm{i}, \mathrm{j})\left({ }^{\circ} \mathrm{C}\right) ; Q_{n}, i j$ means steam condensation heat release of the heat exchanger unit $\mathrm{U}(\mathrm{i}, \mathrm{j}),(\mathrm{kW})$;

\subsubsection{Calculation of saturation temperature in air condenser}

According to the energy balance theorem, the saturation temperature in the air condenser is the weighted average of the saturation temperatures of the heat exchanger units, namely:

$$
t_{n}=\sum_{i=1}^{8} \sum_{j=1}^{7} \frac{D_{\mathrm{n}, \mathrm{j}} t_{\mathrm{n}, \mathrm{ij}}}{D_{\mathrm{n}}}
$$

Where $D_{n, i j}$ is the amount of condensation of the heat exchanger unit $\mathrm{U}(\mathrm{i}, \mathrm{j}),(\mathrm{kg} / \mathrm{s}) ; D_{n}$ is the total amount of condensation of the air-cooled unit $(\mathrm{kg} / \mathrm{s})$;

\subsubsection{Calculation of exhaust steam pressure of direct air-cooled unit}

The saturation temperature and the saturation pressure in the air-cooled unit are in one-to-one correspondence. Under the influence of environmental wind, after obtaining the saturation temperature in the air-cooled unit, the saturation pressure can be calculated as follows:

$$
p_{c}^{\prime}=9.81 \times\left(\frac{t_{\mathrm{n}}+100}{57.66}\right)^{7.46}
$$

Calculate the exhaust pressure of the direct air-cooled unit should consider the impact of the exhaust pressure loss, ie

$$
p_{c}=p_{c}^{\prime}+\Delta p
$$

Where $p_{c}$ means the exhaust pressure of the direct aircooled unit, ( $\mathrm{kPa}$ ); $\Delta p$ meas exhaust pressure loss, mainly including exhaust manifold pressure drop, steam distribution tube pressure drop, cis/reverse tube bundle pressure drop $(\mathrm{kPa})$;

\subsection{Calculation results of exhaust steam pressure under the influence of environmental wind}

In this paper, the exhaust pressure under the influence of environmental wind is calculated, as shown in Figure 4-1. Calculation conditions: the environmental temperature is $14{ }^{\circ} \mathrm{C}$, the exhaust steam is $1260 \mathrm{t} / \mathrm{h}$, the exhaust steam is taken $2410 \mathrm{~kJ} / \mathrm{kg}$, and the fan runs at $100 \%$ speed.

It can be seen from Figure 4-1 that considering the influence of environmental wind, the calculated exhaust steam pressure will increase as the environmental wind speed increases, which is consistent with the actual operation of the site. When the wind speed is small $(<3 \mathrm{~m} / \mathrm{s})$, the influence of environmental wind on the exhaust pressure is small; when the wind speed is higher than $3 \mathrm{~m} / \mathrm{s}$, the influence of environmental wind on the exhaust pressure is increasing with the increase of wind speed.

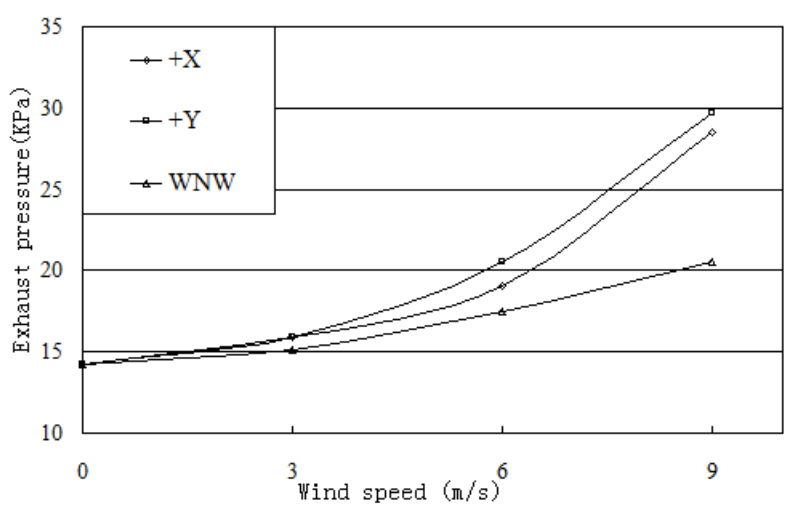

Fig.4-1. Exhaust pressure under the influence of environmental wind

At the same wind speed, the environmental wind in the back wind $(+Y)$ direction has the greatest influence on the exhaust pressure, and the dominant wind direction (WNW) environmental wind has the least influence on the exhaust pressure. In the $+\mathrm{X}$ direction, when the environmental wind rises from $0 \mathrm{~m} / \mathrm{s}$ to $9 \mathrm{~m} / \mathrm{s}$, the exhaust pressure rises by $14.3 \mathrm{kPa}$; in the $+\mathrm{Y}$ direction, when the environmental wind rises from $0 \mathrm{~m} / \mathrm{s}$ to $9 \mathrm{~m} / \mathrm{s}$, The steam pressure increased by $15.5 \mathrm{kPa}$; in the WNW direction, when the environmental wind rose from $0 \mathrm{~m} / \mathrm{s}$ to $9 \mathrm{~m} / \mathrm{s}$, the exhaust pressure increased by $6.4 \mathrm{kPa}$.

\subsection{Thermal economic impact analysis}

Taking the environmental wind in the $+\mathrm{X}$ direction as an example ,analyze the impact of environmental wind impact on the thermal economy of the unit throughout the year. Take a certain area as an example, the wind speed of $0 \mathrm{~m} / \mathrm{s} \sim 3 \mathrm{~m} / \mathrm{s}$ is 7584 hours, the back pressure of the unit is increased by $0.8 \mathrm{kPa}$, the standard coal consumption rate is increased by $1.2 \mathrm{~g} / \mathrm{kW} \cdot \mathrm{h} ; 3 \mathrm{~m} / \mathrm{s} \sim 6 \mathrm{~m}$. $/ \mathrm{s}$ wind speed for the whole year is 1059 hours, the unit back pressure is increased by $3.3 \mathrm{kPa}$, the standard coal consumption rate is increased by $5.0 \mathrm{~g} / \mathrm{kW} \cdot \mathrm{h}$; the $6 \mathrm{~m} / \mathrm{s} \sim 9 \mathrm{~m} / \mathrm{s}$ wind speed is 113 hours for the whole year, and the unit back pressure is averaged increased by $9.6 \mathrm{kPa}$, the standard coal 
consumption rate is increased by $14 \mathrm{~g} / \mathrm{kW} \cdot \mathrm{h}$; the $>9 \mathrm{~m} / \mathrm{s}$ wind speed is 4 hours throughout the year, and the standard coal consumption rate is calculated by increasing $20 \mathrm{~g} / \mathrm{kW} \cdot \mathrm{h}$

If the calculation per ton of standard coal is 200 yuan, the annual average capacity utilization rate of the four 600 MW units is $72 \%$.the environmental wind impact will increase the unit's standard coal consumption by 27,747 tons, and the annual fuel consumption will be 5.55 million yuan.

\section{5 conclusion}

(1) In the $+X$ direction environmental wind, the first row of heat exchanger units on the windward side is prone to backflow; in the $+Y$ direction environmental wind, the first row of heat exchanger units on the windward side is prone to hot air recirculation. As the wind speed increases, the heat transfer efficiency of the air-cooled unit decreases. At the same wind speed, the dominant wind direction (WNW) environmental wind has the least influence on the air-cooled unit, and its heat exchange efficiency is the highest; the furnace later wind $(+\mathrm{Y}$ direction environmental wind) has the greatest influence on the aircooled unit, and its heat exchange efficiency is the least .

(2) The factors affecting the heat transfer efficiency of the direct air-cooled unit are: the temperature rise at the inlet of the fan caused by hot air reflow or backflow, and the existence of the negative pressure zone near the suction port of the fan. Under various working conditions, the dominant factor affecting the heat transfer performance of the air-cooled unit is the reduction of the cooling air volume of the heat exchanger unit caused by the presence of the negative pressure zone. Therefore, in order to improve the heat transfer performance of the aircooled unit under strong wind conditions, it is necessary to reduce the range of the negative pressure zone below the heat exchanger unit and increase the cooling air flow rate of the heat exchanger unit.

(3) Based on the numerical simulation results of each heat exchanger unit, the calculation model of the exhaust pressure of the direct air-cooled unit under the influence of environmental wind is established. After considering the influence of environmental wind, the exhaust steam pressure will increase with the increase of environmental wind speed. When the wind speed is small $(<3 \mathrm{~m} / \mathrm{s})$, the influence of environmental wind on the exhaust steam pressure is small; when the wind speed is higher than $3 \mathrm{~m} / \mathrm{s}$ as the wind speed increases, the influence of environmental wind on the exhaust pressure is increasing.

\section{References}

1. Kong Y, Wang W, Yang L, et al. Thermo - flow Performances of Natural Draft Direct Dry Cooling System at Ambient winds. In-ternational Journal of Heat \& Mass Transfer, 116,173-184 (2018)

2. J.R. Bredell, D.G. Kroger, G.D. Thiart. Numerical investigation of fan performance in a forced draft air- cooled steam condenser. Applied Thermal Engineering.,26, 846-852 (2006)

3. C.J. Meyer. Numerical investigation of the effect of inlet flow distortions on forced draught air-cooled heat exchanger performance. Applied Thermal Engineering,25, 1634-1649 (2005)

4. Duan Huishen, Liu Peiqing, Zhao Wanli. Numerical Simulation of Hot Air Reflux in Direct Air Cooling System of Power Plant Power Engineering, 28,395399 (2008)

5. Peiqing Liu, Huishen Duan, Wanli Zhao. Numerical investigation of hot air recirculation of air-cooled condensers at a large power plant. Applied Thermal Engineering, 29, 1927-1934 (2009).

6. M.T.F. Owen, D.G. Kröger. An investigation of aircooled steam condenser performance under windy conditions using computational fluid dynamics. Journal of Engineering for Gas Turbines and Power, 133, (2011).

7. J.S. Maulbetsch, M.N. DiFilippo. Effects of wind on air-cooled condenser performance. Cooling Technology Institute, Paper no. TP07-04(2007)

8. Cui Chao,Zhao Yuntao,Kong Yanqiang,Yang Lijun. Efficiency improvement for natural draft direct dry cooling system with novel finned tube bundles. Turbine technology, 60,363-367 (2018)

9. L.J. Yang, X.Z. Du, Y.P. Yang. Influences of windbreak wall configurations upon flow and heat transfer characteristics of air-cooled condensers in a power plant. International Journal of Thermal Sciences, 50, 2050-2061 (2011)

10. L.J. Yang, M.H. Wang, X.Z. Du, et al. Trapezoidal array of air-cooled condensers to restrain the adverse impacts of ambient winds in a power plant. Applied Energy. 99, 402-413(2012)

11. L.J. Yang, X.Z. Du, Y.P. Yang. Space characteristics of the thermal performance for air-cooled condensers at ambient winds [J]. International Journal of Heat and Mass Transfer. 54, 3109-3119 (2011)

12. Zhou Lanxin, Li Jianbo, Li Weihua, et al. Numerical simulation of the installation of lower windshield wall for direct air cooling unit condenser. Power Engineering, 28: 744-747 (2008)

13. Zhang Xuelei, Wang Meimei, Zhang Yaozu. Performance analysis and optimization of direct aircooled condenser with the despin-type guide cascades. Proceedings of the CSEE, 38: 4148-4155 (2018)

14. Gu Z F, Li H, Zhang W H, et al. Wind tunnel simulation on recirculation of air-cooled condensers of a power plant. Journal of wind engineering and industrial aerodynamics. 93, 509-520(2005).

15. Gu Z, Chen X R, Lubitz W, et al. Wind tunnel simulation of exhaust recirculation in an air cooling system at a large power plant. International Journal of Thermal Science,46,308-317(2007)

16. X.F. Gao, C.W. Zhang, J.J. Wei, et al.. Numerical simulation of heat transfer performance of an air- 
cooled steam condenser in a thermal power plant [J]. Heat and Mass Transfer. $45: 1423-1433(2009)$

17. W.F. He, Y.P. Dai, J.F. Wang, et al. Performance prediction of an air-cooled steam condenser using UDF method. Applied Thermal Engineering.,50, 1339-1350 (2013)

18. Zhang Xuelei, Wang Jinping, Chen Haiping. Calculation model of exhaust pressure of direct air cooling unit under the influence of ambient wind. Journal of China Electrical Engineering, 32,40-47 (2012) 